\title{
Trends in Resin Composite Restoration Repair Teaching in Dental Colleges in Pakistan
}

\author{
Muhammad Amber Fareed ${ }^{1, \odot}$ Anam Fayyaz Bashir ${ }^{2}$ \\ Ussamah Waheed Jatala ${ }^{5}$ Muhammad Sohail Zafar ${ }^{6}$ \\ ${ }^{1}$ Adult Restorative Dentistry, Dental Biomaterials and \\ Prosthodontics, Oman Dental College, Muscat, Sultanate of Oman \\ 2Department of Operative Dentistry, Lahore Medical and Dental \\ College, Lahore, Pakistan \\ ${ }^{3}$ Department of Orthodontics, University College of Medicine and \\ Dentistry, The University Of Lahore, Lahore, Pakistan \\ ${ }^{4}$ Department of Community Dentistry, Dow International Dental \\ College, Dow University of Health Sciences, Karachi, Pakistan \\ ${ }^{5}$ Department of Prosthodontics, Lahore Medical and Dental \\ College, Lahore, Pakistan \\ ${ }^{6}$ Department of Restorative Dentistry, College of Dentistry, Taibah \\ University, Al Madinah, Al Munawwarah, Saudi Arabia
}

\author{
Usman Yousaf ${ }^{3}$ Qaiser Ali Baig ${ }^{4}$
}

Eur J Gen Dent 2021;10:14-18.

\section{Abstract}

\section{Keywords}

- composite repair

- defective restoration

- minimally invasive dentistry

- teaching
Objective The paradigm shift from replacement to repair of defective resin composite restorations to implement minimal intervention approaches has been popular. Therefore, the teaching of composite repair strategies is included in contemporary dental curricula across the globe.

Methods A validated 18-item questionnaire pertaining to existing educational practices related to the teaching of defective composite restorations repair was acquired form dental colleges in Pakistan.

Results The response rate was $63 \%$ and the majority of dental colleges (67\%) reported that they have included the teaching of composite restorations repair in the curricula, where four colleges (33\%) implemented only didactic teaching and eight colleges (66\%) reported a combination of didactic teaching and clinical training. The composite repair indications taught included tooth substance conservation $100 \%$ (12), reduced cost to patient $84.3 \%$ (10) and dentist $100 \%(12)$, reduced iatrogenic pulpal damage $100 \%$ (12), and reduced chair side treatment time $91.3 \%$ (11), restoration-related defects (66\% preferred repair), anterior tooth fracture from incisal/proximal margin (80\% teach repair), and in case of posterior tooth cusp fracture ( $20 \%$ teach repair). Our results revealed that the choice of mechanical and adhesive substrate surface conditioning depended on case selection.

Conclusion The teaching of defective composite restorations repair was less widespread and certain variations in teaching were identified. Nearly all dental colleges reported to incorporate current evidence of minimum invasive strategies of composite repair in curricula in future.
DOI https://doi.org/

$10.1055 / \mathrm{s}-0041-1732770$

ISSN 2320-4753 (c) 2021. European Journal of General Dentistry.

This is an open access article published by Thieme under the terms of the Creative Commons Attribution-NonDerivative-NonCommercial-License, permitting copying and reproduction so long as the original work is given appropriate credit. Contents may not be used for commercial purposes, or adapted, remixed, transformed or built upon. (https://creativecommons.org/licenses/by-nc-nd/4.0/).

Thieme Medical and Scientific Publishers Pvt. Ltd. A-12, 2nd Floor, Sector 2, Noida-201301 UP, India 


\section{Introduction}

Teaching of resin composite materials is a fundamental component of the dental curriculum for the restoration of both anterior and posterior teeth. Several type of possible defects inevitably may occur during the service life in composite restorations which require either repair or replacement of existing defective restoration. ${ }^{1-4}$ Therefore, minimally invasive dentistry has encouraged and promoted repair rather than replacement of faulty composite restoration. ${ }^{1,2}$ Replacement of a composite restoration is defined as the complete removal of the existing failed or defective restoration that was functionally or aesthetically unacceptable. Whereas composite repair is refurbishment or repair of a part of existing defective restoration, adjacent caries, or an unendurable discolored restoration aesthetically or functionally. ${ }^{3}$ It is established that composite repair is a conservative approach that provides the management of defective composite restorations with numerous clinical advantages. ${ }^{4-8}$ Previous studies on teaching of composite restoration repair surveys conducted in several countries are shown in - Table $\mathbf{1}$. Several dental schools teaching composite repair in the United Kingdom and Ireland, ${ }^{5-7}$ United States, Canada, Puerto
Rico, ${ }^{8,9}$ Scandinavia, ${ }^{7,10,11}$ Germany, ${ }^{7,12,13}$ Brazil, ${ }^{14}$ Pakistan, ${ }^{15}$ Japan, ${ }^{16}$ Australia, Fiji, New Zealand, and Papua New Guinea ${ }^{17}$ provided a sufficient evidence and have demonstrated a gradual increase in clinical and didactic teaching on restoration repair of partially defective composite restoration in adult patients. ${ }^{4-15}$

Most of the studies mentioned in - Table 1 have had employed survey questionnaire developed by Blum at el.,7 Several parameters and justification for teaching repair and suggesting guidelines of repair versus replacement and the biologically driven minimally invasive approaches to resin composite restoration have been taught in most dental curriculum all over the world. ${ }^{16}$ Brunton et al argued that there is currently no unanimous practice guidelines available on the indications and operative techniques for the repair of restorations despite the wide spread popularity of minimally invasive dentistry. ${ }^{17}$ Likewise, Kanzow et al recommended that national/international scientific societies and work groups in operative and restorative dentistry should produce guidelines on "key treatment steps" of defective composite restoration repair having uniform protocol to improve teaching composite repair topic. ${ }^{18}$ Moreover, a variety of factors influence the decision making related to repair or replacement

Table 1 Earlier surveys conducted in several countries on teaching practices of the repair of resin composite restoration showing the response rate of dental schools reported teaching composite repair

\begin{tabular}{|c|c|c|c|c|}
\hline $\begin{array}{l}\text { Authors } \\
\text { (Publication year) }\end{array}$ & Country surveyed & $\begin{array}{l}\text { Response rate of dental } \\
\text { school (\%) }\end{array}$ & $\begin{array}{l}\text { Dental school } \\
\text { teaching repair (\%) }\end{array}$ & Reference \\
\hline $\begin{array}{l}\text { Blum et al } \\
(2002)\end{array}$ & \multirow[t]{2}{*}{ UK, Ireland } & $\begin{array}{l}15 \text { of } 15 \\
(100 \%)\end{array}$ & $\begin{array}{l}14 \text { of } 15 \\
(93 \%)\end{array}$ & 5 \\
\hline $\begin{array}{l}\text { Blum et al } \\
(2012)\end{array}$ & & $\begin{array}{l}17 \text { of } 17 \\
(100 \%)\end{array}$ & $\begin{array}{l}15 \text { of } 17 \\
(88 \%)\end{array}$ & 6 \\
\hline $\begin{array}{l}\text { Blum et al } \\
\text { (2003) }\end{array}$ & $\begin{array}{l}\text { UK, Ireland, Germany, and } \\
\text { Scandinavia }\end{array}$ & $\begin{array}{l}48 \text { of } 58 \\
(83 \%)\end{array}$ & $\begin{array}{l}35 \text { of } 48 \\
(73 \%)\end{array}$ & 7 \\
\hline $\begin{array}{l}\text { Gordan et al } \\
\text { (2003) }\end{array}$ & \multirow[t]{2}{*}{$\begin{array}{l}\text { North America } \\
\text { (USA, Canada, Puerto Rico) }\end{array}$} & $\begin{array}{l}52 \text { of } 64 \\
(81 \%)\end{array}$ & $\begin{array}{l}37 \text { of } 52 \\
(71 \%)\end{array}$ & 8 \\
\hline $\begin{array}{l}\text { Lynch et al } \\
(2012)\end{array}$ & & $\begin{array}{l}48 \text { of } 67 \\
(72 \%)\end{array}$ & $\begin{array}{l}42 \text { of } 48 \\
(88 \%)\end{array}$ & 9 \\
\hline $\begin{array}{l}\text { Blum et al } \\
\text { (2003) }\end{array}$ & \multirow[t]{2}{*}{ Scandinavia } & $\begin{array}{l}9 \text { of } 11 \\
(91 \%)\end{array}$ & $\begin{array}{l}9 \text { of } 9 \\
(100 \%)\end{array}$ & 10 \\
\hline $\begin{array}{l}\text { Blum et al } \\
(2012)\end{array}$ & & $\begin{array}{l}12 \text { of } 12 \\
(100 \%)\end{array}$ & $\begin{array}{l}11 \text { of } 12 \\
(92 \%)\end{array}$ & 11 \\
\hline $\begin{array}{l}\text { Blum et al } \\
(2011)\end{array}$ & \multirow[t]{2}{*}{ Germany } & $\begin{array}{l}22 \text { of } 25 \\
83 \%\end{array}$ & $88 \%$ & 13 \\
\hline $\begin{array}{l}\text { Kanzow et al } \\
(2018)\end{array}$ & & $\begin{array}{l}28 \text { of } 29 \\
(97)\end{array}$ & $\begin{array}{l}26 \text { of } 28 \\
(90 \%)\end{array}$ & 12 \\
\hline $\begin{array}{l}\text { Tovo et al } \\
(2011)\end{array}$ & Brazil & $\begin{array}{l}6 \text { of } 8 \\
(75 \%)\end{array}$ & $\begin{array}{l}6 \text { of } 6 \\
(100 \%)\end{array}$ & 14 \\
\hline $\begin{array}{l}\text { Hasan et al } \\
(2011)\end{array}$ & Pakistan & $\begin{array}{l}9 \text { of } 10 \\
(90 \%)\end{array}$ & $\begin{array}{l}8 \text { of } 9 \\
(89 \%)\end{array}$ & 15 \\
\hline $\begin{array}{l}\text { Lynch et al } \\
(2013)\end{array}$ & Japan & $\begin{array}{l}19 \text { of } 29 \\
(66 \%)\end{array}$ & $\begin{array}{l}18 \text { of } 19 \\
(95 \%)\end{array}$ & 16 \\
\hline $\begin{array}{l}\text { Brunton et al } \\
(2017)\end{array}$ & Oceania & $\begin{array}{l}16 \text { of } 16 \\
(100 \%)\end{array}$ & $\begin{array}{l}13 \text { of } 16 \\
(81 \%)\end{array}$ & 17 \\
\hline $\begin{array}{l}\text { Kanzow et al } \\
(2018)\end{array}$ & $\begin{array}{l}\text { Systematic review and } \\
\text { meta-analysis }\end{array}$ & 276 & $\begin{array}{l}229 \text { of } 226 \\
(83 \%)\end{array}$ & 18 \\
\hline
\end{tabular}


of a defective restoration due to marked variations such as the criteria and indications of a clinical condition, the selection of a restorative material, associated cost-effectiveness, and techniques taught for the repair. ${ }^{17-19}$ As an alternative to replacement of defective restoration of faulty composite restorations, composite repair technique could possibly be considered by using resin-based composite material through a careful surface treatment and application of appropriate bonding agents to improve the longevity of the restorations. ${ }^{17}$ In this regard, it is reasonable to assume that such evidences and concepts of teaching resin composite repair would be translated into dental school curriculum. ${ }^{18}$ Therefore, the objective of this article is to explore the existing teaching practices in relation to the management of defective direct composite restorations in undergraduate dental colleges in Pakistan and to evaluate the teaching practices related to direct composite restoration repair.

\section{Materials and Methods}

An 18-item survey questionnaire associated to teaching of defective resin composite restoration management was distributed to operative dentistry departments in 19 dental colleges across Pakistan. This questionnaire was prepared similar to the Blum et al seeking the information on the techniques and practices related to composite repair teaching., ${ }^{9,20}$ The printed questionnaire requested information concerning teaching of direct resin composite restoration repair techniques, teaching methods (didactically and/or clinically), indications for restoration repair taught, and presumed longevity of repaired restorations. We recommended respondents responsible for teaching to complete this questionnaire as "faculty team of operative dentistry" to give a collective agreed opinion. It was also specified that no individual college would be identified in any publications.

\section{Results}

The completed replies were received from 12 of the 19 dental colleges (response rate $=63 \%$ ). Eight dental colleges $(67 \%)$ reported that they have incorporated repair of defective resin composite restorations in their teaching curriculum. Whereas four dental schools (33\%) did not teach repair because either there were no assessments involved in the university examination $(50 \%)$ or composite repair was not included in the curriculum (50\%). However, all dental schools not teaching composite repair reported that they plan to introduce the topic of composite repair in coming years. According to our results seven dental schools $(58.3 \%)$ use the evidence from clinical and minimal intervention dentistry whereas five dentals schools (41.7\%) use existing literature and case reports to support the evidence of repair.

- Table 2 summarizes the indications for composite repair and replacement that were reported. The reason of teaching repair or replacement of defective restoration were restoration-related defects (caries associated with restoration and sealants) and majority (66\%) of dental school schools preferred repair rather than replacement (33\%) in this case.
Table 2 Teaching repair or replacement of defective composite restorations in different clinical situations, as reported by different dental colleges $(n=12)$

\begin{tabular}{|l|l|l|}
\hline \multirow{2}{*}{ Clinical situations } & Repair & Replace \\
\cline { 2 - 3 } & $n=12(\%)$ & $n=12(\%)$ \\
\hline Restoration-related defects (caries) & $8(66.3)$ & $33.3(4)$ \\
\hline $\begin{array}{l}\text { Marginal defect in a previous com- } \\
\text { posite restoration }\end{array}$ & $6(50)$ & $6(50)$ \\
\hline $\begin{array}{l}\text { Partial surface loss of a class II } \\
\text { composite restoration }\end{array}$ & $7(58.3)$ & $5(41.7)$ \\
\hline $\begin{array}{l}\text { Discolored composite restoration } \\
\text { in maxillary central incisor }\end{array}$ & $6(50)$ & $6(50)$ \\
\hline $\begin{array}{l}\text { Anterior tooth fracture from } \\
\text { incisal/proximal margin }\end{array}$ & $10(80)$ & $2(20)$ \\
\hline Posterior tooth cusp fracture & $2(20)$ & $10(80)$ \\
\hline
\end{tabular}

Similarly, in a situation of anterior tooth fracture from incisal/proximal margin $80 \%$ teach repair and $20 \%$ replacement of defective composite. However, in case of posterior tooth cusp fracture repair was the least popular option (20\%).

Teaching of repair to undergraduate student involved didactic teaching only in four schools (33\%) while a combination of didactic teaching and clinical training procedures was stated by eight schools (66\%). Our results implied that the majority of dental schools agreed or strongly agreed that repair rather than replacement of a defective resin composite restoration benefited in tooth substance conservation $100 \%$ (12), reduce cost to patient $84.3 \%$ (10) and dentist $100 \%$ (12), reduce iatrogenic pulpal damage $100 \%$ (12), and reduced chair side treatment time $91.3 \%$ (11). Respondents provided information about the materials and techniques taught at their schools for repairing defective direct resin-based composite restorations, given in - Table $\mathbf{3}$. The expected longevity of a repaired composite restoration having marginal defects was reported to be less than 6 months in three schools (25\%) and more than 1 year in nine schools (75\%). While teaching about the selection of materials and techniques used for composite repair in a given clinical situation the recommendation taught were nanohybrid composite (58.2\%), acid etching with phosphoric acid, and finishing discs (41.7\%).

\section{Discussion}

The purpose of this study was to examine the teaching practices and techniques of composite repair in dental colleges in Pakistan and to ascertain variations in relation to indications and teaching techniques. The authors conceded the inherent limitations of data collection by means of these types of surveys. There are associated perceived restraints due to response rate and the results presented may not provide a comprehensive abridgment of approaches toward composite repair teaching across Pakistan. However, findings of the present study complement the current knowledge on composite repair teaching. Although we collected the data regarding the teaching of composite repair both in theoretical and clinical teaching session, the supplementary information related to the precise nature of teaching and number of dedicated hours 
Table 3 The choice of materials and techniques taught to repair defective composites restoration, as reported by dental colleges $(n=12)$

\begin{tabular}{|l|l|}
\hline Materials and techniques & $\begin{array}{l}\text { \% Respondent } \\
(\boldsymbol{n}=12)\end{array}$ \\
\hline $\begin{array}{l}\text { The choice of repair material for a defective } \\
\text { composite restoration: }\end{array}$ & $58.3(7)$ \\
\hline Nanohybrid composites & $16.7(2)$ \\
\hline Microhybrid composites & $25.0(3)$ \\
\hline Flowable composite & \\
\hline $\begin{array}{l}\text { The surface treatment for defective compos- } \\
\text { ite repair: }\end{array}$ & $41.7(5)$ \\
\hline $\begin{array}{l}\text { Mechanical roughening/removal of } \\
\text { surface }\end{array}$ & $41.7(5)$ \\
\hline Acid etching with phosphoric acid & $8.3(1)$ \\
\hline Cleaning with slurry of pumice & $8.3(1)$ \\
\hline No mechanical surface treatment & \\
\hline Finishing techniques for composite repair: & $25.0(3)$ \\
\hline Using diamond finishing instruments & $16.7(2)$ \\
\hline Polishing points & $41.7(5)$ \\
\hline Finishing discs & $8.3(1)$ \\
\hline Tungsten carbide finishing instruments & $8.3(1)$ \\
\hline Polishing paste & \\
\hline
\end{tabular}

of this teaching in lectures, seminars, clinical simulation, and clinical instruction was not gathered and can potentially be focused on in future studies. In our survey $73.3 \%$ dental colleges reported that they have included repair of defective resin composite restorations in their teaching curriculum, this is lesser than the average value reported in a recent meta-analysis of restoration repair teaching which indicated that $83 \%$ international dental schools included restoration repair in their curricula. ${ }^{18}$ This excellent systematic review of surveys on the management and teaching of dental restoration repair concluded that the concept of composite restoration repair have had been incorporated in a vast majority of dental curricula of several countries and many dental schools do teach composite repair concepts, but authors also claimed that the actually performed proportion of restoration repair seems low. ${ }^{18}$ The research performed during the past two decades on the teaching of resin composite restoration repair have provided sufficient evidence of significant increase in clinical and didactic teaching of defective composite restoration repair. ${ }^{4-13}$

Previously, Hasan et al reported that teaching of composite repair procedures was conducted at clinical level (63\%) and at preclinical level (21\%) in dental colleges in Karachi. ${ }^{15}$ Likewise, the results of our study on teaching of repair to undergraduate student showed that four schools (33\%) implemented didactic teaching only whereas a combination of didactic teaching and clinical training procedures was reported by eight dental schools (66\%). Whereas four dental schools (26.7\%) did not teach repair because either there were no assessments involved or composite repair was not included in the curriculum. However, all dental schools not teaching composite repair plan to introduce the topic of composite repair in coming years.

Kanzow at el conducted a study on restoration repair teaching at German dental schools and reported that the most indications for teaching restoration repairs were preservation of tooth structure (97\%) and pulpal damage reduction (79\%). ${ }^{12}$ Similarly, a retrospective analysis of composite restorations repair versus replacement reported an increased survival of composite restorations and interestingly repaired restorations last as long as replacement of restorations. ${ }^{19,21}$

Composite restoration repair protocols have been developed as a result of several previous surveys on teaching of composites repair ( $\mathbf{- T a b l e} \mathbf{1}$ ) and advancements in adhesive and minimum invasive dentistry. ${ }^{12-19,21}$ Moreover, our preceding study suggested that most general dental practitioners are inclined toward replacement of defective composite restoration. ${ }^{20}$ Similarly, most recent surveys on composite repair described that a large number of dentists declared to repair composite restorations based on self-reported data and it was not confirmed when assessing how defective restorations were managed clinically. $22-24$ The criteria to perform composite repair in dental practice also reported that the use of diamond burs for surface roughening, air abrasion, or silica coating were considered along with the application of a silane coupling agent, primer, and an adhesive as mandatory., ${ }^{4,1821-24}$

Restoration-related defects and anterior tooth fracture from incisal/proximal margin was the foremost indications for performing repair of composite restoration in our study. Comparable findings were reported in former survey reports highlighting the importance of repair not only in functional failure but also in biological failure. ${ }^{5-17}$ The results of our study indicated that dental school are well aware of the need appropriate surface treatment (both mechanical and adhesive); however, the need of air abrasion for surface treatment while performing composite repair was not enquired. Besides, the contemporary clinical repair protocols recommend the use of air abrasion for mechanical surface treatment for the repair of partially defective resin composite..$^{22-24}$

Recently, FDI World Dental Federation published a policy statement to support developing protocols for defective restorations repair and recommend it to be incorporated in undergraduate curriculum and continuing education..$^{25}$ In our study, it was interesting that one of the replies included a comment that one of reasons for not recommending composite repair in teaching was "the personal concerns regarding the students performing composite repair of affected restoration." However, in spite of the teaching of repair rather than replacement of defective resin composite restorations, it is unclear as to what extent this technique is applied in clinical dental practice in dental school in Pakistan. Therefore, the impact of this teaching on subsequent dental practices should be investigated to benefit the patients. It is assumed that teaching practices related with composite repair may possibly be associated behavior change from replacement to repair has not taken place uniformly in most dental schools across Pakistan. It is recommended that integration of teaching of composite repair strategies with the practices of minimum invasive dentistry in dental school curricula will 
precedence to increase the confidence in repair techniques to be advantageous for patients and dentist alike. Nonetheless, it is anticipated that restorative dentistry faculty would continue to encourage, develop, and refine composite repair guidelines.

\section{Conclusion}

There is evidence that teaching repair rather than the replacement of defective composite restorations was considered appropriated in majority of dental colleges. Caries associated with resin composite restorative, marginal defects, and anterior tooth incisal or proximal margin defects were the leading indications taught to students when considering repair of composite restoration. Although not all the dental schools are teaching composite repair, but it is encouraging that they reported plans to introduce repair topic in future. However, teaching methodologies of clinical indications and operative technique to perform composite repair require further exploration to have a conclusive response.

\section{Funding}

This research received no external funding.

\section{Conflict of Interest}

The authors declare no conflicts of interest.

\section{References}

1 Lynch CD, Frazier KB, McConnell RJ, Blum IR, Wilson NHF. Minimally invasive management of dental caries: contemporary teaching of posterior resin-based composite placement in U.S. and Canadian dental schools. J Am Dent Assoc 2011;142(6):612-620

2 Kanzow P, Wiegand A. Retrospective analysis on the repair vs. replacement of composite restorations. Dent Mater 2020;36(1):108-118

3 Opdam NJM, Collares K, Hickel R, et al. Clinical studies in restorative dentistry: new directions and new demands. Dent Mater 2018;34(1):1-12

4 Ritter AV, Lee W, Boushell RW. Sturdevant's Art \& Science of Operative Dentistry. 7th edition. St. Louis, MO: Elsevier; 2019

5 Blum IR, Schriever A, Heidemann D, Mjör IA, Wilson NHF. Repair versus replacement of defective direct composite restorations in teaching programmes in United Kingdom and Irish Dental Schools. Eur J Prosthodont Restor Dent 2002;10(4):151-155

6 Blum IR, Lynch CD, Wilson NHF. Teaching of direct composite restoration repair in undergraduate dental schools in the United Kingdom and Ireland. Eur J Dent Educ 2012;16(1):e53-e58

7 Blum IR, Schriever A, Heidemann D, Mjör IA, Wilson NHF. The repair of direct composite restorations: an international survey of the teaching of operative techniques and materials. Eur J Dent Educ 2003;7(1):41-48

8 Gordan VV, Mjör IA, Blum IR, Wilson N. Teaching students the repair of resin-based composite restorations: a survey of North American dental schools. J Am Dent Assoc 2003;134(3):317-323, quiz 338-339

9 Lynch CD, Blum IR, Frazier KB, Haisch LD, Wilson NHF. Repair or replacement of defective direct resin-based composite restorations: contemporary teaching in U.S. and Canadian dental schools. J Am Dent Assoc 2012;143(2):157-163

10 Blum IR, Mjör IA, Schriever A, Heidemann D, Wilson NHF. Defective direct composite restorations-replace or repair? A survey of teaching in Scandinavian dental schools. Swed Dent J 2003;27(3):99-104

11 Blum IR, Lynch CD, Wilson NHF. Teaching of the repair of defective composite restorations in Scandinavian dental schools. J Oral Rehabil 2012;39(3):210-216

12 Kanzow P, Wiegand A, Wilson NHF, Lynch CD, Blum IR. Contemporary teaching of restoration repair at dental schools in Germany - close to universality and consistency. J Dent 2018;75:121-124

13 Blum IR, Lynch CD, Schriever A, Heidemann D, Wilson NHF. Repair versus replacement of defective composite restorations in dental schools in Germany. Eur J Prosthodont Restor Dent 2011;19(2):56-61

14 Tovo CB, de Castilhos ED, Rodrigues-Junior SA. Repair of composite restorations - teaching information from dental schools of the State of Rio Grande do Sul (RS), Brazil. RFO, Passo Fundo 2011;16(3):301-306 doi:10.5335/rfo.v16i3.1000

15 Hasan M, Khan F, Rahman M. Teaching and practice of repair of resin composite restorations in dental institutions of Karachi. JPDA 2011;20:216-221

16 Lynch CD, Hayashi M, Seow LL, Blum IR, Wilson NHF. The management of defective resin composite restorations: current trends in dental school teaching in Japan. Oper Dent 2013;38(5):497-504

17 Brunton PA, Ghazali A, Tarif ZH, et al. Repair vs replacement of direct composite restorations: a survey of teaching and operative techniques in Oceania. J Dent 2017;59:62-67

18 Kanzow P, Wiegand A, Göstemeyer G, Schwendicke F. Understanding the management and teaching of dental restoration repair: systematic review and meta-analysis of surveys. J Dent 2018;69:1-21

19 Casagrande L, Laske M, Bronkhorst EM, Huysmans MCDNJ, Opdam NJM. Repair may increase survival of direct posterior restorations - a practice based study. J Dent 2017;64:30-36

20 Fayyaz A, Fareed MA, Ehsan S, Baig QA, Noor NA. Repair or replacement of defective direct composite restorations: a survey of dentists. J Pak Dent Assoc 2015;24:17-21

21 Fernández E, Martín J, Vildósola P, et al. Can repair increase the longevity of composite resins? Results of a 10-year clinical trial. J Dent 2015;43(2):279-286

22 Kanzow P, Wiegand A. Teaching of composite restoration repair: trends and quality of teaching over the past 20 years. J Dent 2020;95:103303

23 Blum IR. Restoration repair as a contemporary approach to tooth preservation: criteria for decision making and clinical recommendations. Prim Dent J 2019;8(1):38-42

24 Hickel R, Brüshaver K, Ilie N. Repair of restorations-criteria for decision making and clinical recommendations. Dent Mater 2013;29(1):28-50

25 Fdi World Dental Federation. Repair of restorations: adopted by the General Assembly: September 2019, San Francisco, United States of America. Int Dent J 2020;70(1):7-8 